\title{
Protection of Chinese painted quails (Coturnix chinensis) against a highly pathogenic H5N1 avian influenza virus strain after vaccination
}

\author{
Julia Sarkadi • Mate Jankovics · Zoltan Kis • \\ Jozsef Skare • Kinga Fodor • Eva Gonczol • \\ Ildiko Visontai · Zoltan Vajo • Istvan Jankovics
}

Received: 11 March 2013/Accepted: 27 April 2013/Published online: 15 June 2013

(c) The Author(s) 2013. This article is published with open access at Springerlink.com

\begin{abstract}
Chinese painted quails immunized with a single dose (6 $\mu \mathrm{g} \mathrm{HA})$ of inactivated H5N1 (clade 1) influenza vaccine NIBRG-14 and challenged with $100 \mathrm{LD}_{50}$ of the heterologous A/Swan/Nagybaracska/01/06(H5N1) (clade 2.2) strain were protected, whereas unvaccinated quails died after challenge. No viral antigens or RNA were detected in cloacal swabs from immunized animals. Sera obtained post-immunization gave low titres in serological assays against the vaccine and the challenge viruses. Our results demonstrate the protective efficacy of the NIBRG-14 strain against the challenge virus and the usefulness of these small birds in protection studies of influenza vaccines.
\end{abstract}

Keywords Chinese painted quails - HPAI H5N1 strains . NIBRG-14 vaccine · A/Swan/Nagybaracska/01/06(H5N1) challenge virus

Highly pathogenic avian influenza virus (HPAI) strains cause significant mortality in unvaccinated chickens, but their virulence varies in mammals, and mutations in certain viral genes coding for structural and non-structural proteins contribute to virulence [7, 14, 18]. HPAI strains also cause human infections with high mortality rates, some with a high probability of human-to-human transmission, and they are thus a constant threat to humans [27].

J. Sarkadi - M. Jankovics $\cdot$ Z. Kis · J. Skare $\cdot$ K. Fodor .

E. Gonczol · I. Visontai · I. Jankovics ( $\square)$

Division of Virology, National Center for Epidemiology,

Budapest 1097, Hungary

e-mail: jankovics.istvan@oek.antsz.hu

\section{Z. Vajo}

Medical and Health Science Center, University of Debrecen, Debrecen 4032, Hungary
When the mammalian virulence of HPAI H5N1 strains, including human isolates, was tested either in mice or in ferrets, these strains proved to be highly pathogenic or caused only mild or no symptoms. Few studies have measured virulence in both mice and ferrets; some strains have displayed similar pathogenicity in both animals, but other HPAI strains have exhibited virulence differences, especially at high doses [4, 18, 21, 33]. Inbred mouse strains vary considerably in their ability to resist the H5N1 virus, and the distinct expression profiles of inflammatory mediators have been suggested to control disease severity [1]. Such observations indicate that results obtained in H5N1 mammalian protection models can vary with the animal species and the dose and type of the experimentally applied challenge virus.

The immunogenicity and protection-conferring ability of a candidate vaccine virus, NIBRG-14 (clade 1), have been evaluated in mammalian model systems. The protective effect of the anti-haemagglutinin (HA) and antineuraminidase (NA) antibodies in BALB/c mice was shown by injecting the serum into severe combined immunodeficiency mice, which were then challenged with a homologous highly pathogenic H5N1 virus strain [25]. Immunization with the adjuvanted NIBRG-14 vaccine strain conferred protection in mice or monkeys against a lethal challenge with homologous or heterologous strains $[9,10,22]$. In humans, one injection of the NIBRG-14 vaccine triggered antibody responses that cross-reacted with clade $2 \mathrm{H} 5 \mathrm{~N} 1$ strains, including the A/Swan/Nagybaracska/01/06(H5N1) reassortant strain, in in vitro serological assays [6]. These earlier results demonstrated the cross-clade efficacy of the NIBRG-14 vaccine strain.

Animal model systems that met the requirements of high susceptibility to a great variety of $\mathrm{H} 5 \mathrm{~N} 1$ viruses, easy animal handling, and fast, cost-effective and reliable results 
are still needed. The HPAI H5N1 strains tested so far were all pathogenic in chickens $[8,17]$ and Japanese quails (Coturnix-japonica) [11, 13, 19, 32]. The Chinese painted quail (Coturnix-chinensis, formerly Excalfactoria chinensis, in the family Phasianidiae of the order Galliformes) is the smallest "true quail", common worldwide in aviculture; the average weight of the adult male and female is about 48 and $56 \mathrm{~g}$, respectively. Chinese painted quails are superior to chickens and Japanese quails due to their ease of handling and general care, hardiness, excellent reproductive performance, and less expensive maintenance [26]. Importantly, Chinese painted quails are smaller in size than chickens and Japanese quails. Using Chinese painted quails for vaccine studies with HPAI H5N1 viruses that require enhanced biosafety level 3 (BSL-3+) conditions provides a reasonable opportunity for the inclusion of the birds in appropriate numbers and groups in the experiments, thus achieving scientifically acceptable results. Quails carry sialic acid receptors with the potential of binding of avian and human influenza viruses, thereby serving as an intermediate host for the zoonotic transmission of influenza viruses [30] and potentially as a challenge system for human and avian influenza virus vaccines. We are not aware of published results on the use of Chinese painted quails in influenza vaccine research.

We set out to investigate the possible usefulness of the Chinese painted quail in $\mathrm{H} 5 \mathrm{~N} 1$ vaccine studies. We demonstrated the high pathogenicity of the wild-type A/Swan/ Nagybaracska/01/06(H5N1) (clade 2.2) strain in Chinese painted quails and the protective effect of vaccination with the NIBRG-14 strain (clade 1) against this heterologous strain, demonstrating for the first time that Chinese painted quails are useful, reliable, and economically and technically tractable for measuring the protective effect of vaccination against $\mathrm{H} 5 \mathrm{~N} 1$ viruses.

In our experiments, 10-week-old Chinese painted quails that were seronegative for currently circulating influenza A and B viruses (K.A.G. Technologies Ltd, Hungary) were immunized with the NIBRG-14 H5N1 (clade 1) strain and challenged with the A/Swan/Nagybaracska/01/06(H5N1) (clade 2.2) strain at week 3 or 6 after immunization.

The NIBRG-14 virus strain, obtained from the National Institute for Biological Standards and Control, London, $\mathrm{UK}$, is a reverse-genetics-derived 2:6 reassortant and one of the available and proposed candidate A (H5N1) vaccines [5]. The seed virus was grown in eggs. The formaldehydeinactivated whole-virus vaccine, produced by Omninvest Ltd., Hungary, contained $6 \mu \mathrm{g}$ HA and $0.3 \mathrm{mg}$ aluminum phosphate adjuvant/dose. The preparation and immunogenicity of the vaccine in humans were described earlier $[6$, 28, 29].

The HPAI challenge strain, influenza A/Swan/Nagybaracska/01/06(H5N1), a wild-type avian influenza virus, was isolated in Hungary and shown to belong to clade 2.2 on the basis of HA sequences [6]. The TCID 50 of the virus was determined by titration in Madin-Darby canine kidney cells. To determine the $\mathrm{LD}_{50}$, birds were inoculated subcutaneously (s.c.) with serial dilutions of the virus in a volume of $100 \mu \mathrm{l}, 4$ birds for each dilution, and monitored daily for morbidity and mortality for 2 weeks. The TCID 50 and $\mathrm{LD}_{50}$ titres were calculated by the method of Reed and Muench [23] and compared; $50 \mathrm{TCID}_{50}$ were required to give one $\mathrm{LD}_{50}$ in Chinese painted quails.

The immunization and challenge experiments were conducted in the BSL-3+ containment facility at the National Center for Epidemiology, as approved for such use by the Chief Medical Officer of Hungary. The facility was secured by procedures recognized as appropriate by the institutional biosafety officers, facility management and Laboratory Animal Care Committee as well as Hungarian government inspectors. The Chinese painted quails were housed in individually ventilated cages used conventionally for mouse experiments (4 birds/cage).

In the first experimental series, 12 birds were immunized s.c. twice at an interval of 3 weeks with the NIBRG14 strain in a volume of $100 \mu \mathrm{l}$ and challenged s.c. in 3 groups of 4 animals at week 6 with 1 or $10 \mathrm{LD}_{50}$ of the

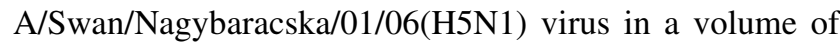
$100 \mu$ l. Three of the 4 unimmunized control birds that received $1 \mathrm{LD}_{50}$ and all four of the unimmunized animals that received $10 \mathrm{LD}_{50}$ of the challenge virus died within 8 days post-challenge. All of the immunized birds survived and remained healthy, demonstrating the protective effect of the twice-inoculated vaccine virus.

In the second experimental series, 24 birds were immunized with a single dose of the vaccine strain. Three weeks later, 8 birds were bled for serologic testing, and 16, in 2 groups of 8 animals, were challenged with 10 or 100 $\mathrm{LD}_{50}$ of strain A/Swan/Nagybaracska/01/06(H5N1). Sixteen unimmunized quails, 8 per group, served as controls and were challenged similarly. All birds in the unvaccinated control groups died within 8 days post-challenge, while all vaccinated quails remained healthy and showed no clinical signs of illness (Fig. 1). The unvaccinated group challenged with the 10 or $100 \mathrm{LD}_{50}$ dose displayed depression, reluctance, decreases in food and water consumption, and increased respiratory rates at $24 \mathrm{~h}$ postchallenge. At $48 \mathrm{~h}$ and $96 \mathrm{~h}$, the clinical signs were similar, but the weakness and drowsiness were more pronounced, and diarrhoea occurred.

Cloacal swab samples from immunized and unimmunized animals were analysed for the presence of viral antigens and RNA. The RapidSignal ${ }^{\mathrm{TM}}$ Influenza H5 Dipstrip (Orgenics Ltd., Israel) chromatographic immunoassay was used to detect $\mathrm{H} 5$ virus antigens according to the instructions of the manufacturer. RNA was extracted with 
Tri-Reagent (Sigma-Aldrich, St. Louis, MO, USA), and reverse transcription was performed with avian transcriptase according to the manufacturer's instructions (Applied Biosystems Foster City, CA, USA). REDTaq ReadyMix PCR Reaction Mix with $\mathrm{MgCl}_{2}$ (Sigma-Aldrich) was used in the PCR with a primer pair corresponding to the M segment; positive results were confirmed with specific H5 primers [31]. The results showed that $\mathrm{H} 5$ viral antigens were present in the cloacal swabs of all the unvaccinated control birds. Those unvaccinated and challenged with 100 $\mathrm{LD}_{50}$ were PCR positive, demonstrating the presence of viral RNA in the samples. All samples obtained from immunized and challenged animals were negative for $\mathrm{H} 5$ viral antigens and RNA (Table 1). Oropharingeal swabs were not taken from the birds for analysis of viral antigens and RNA.

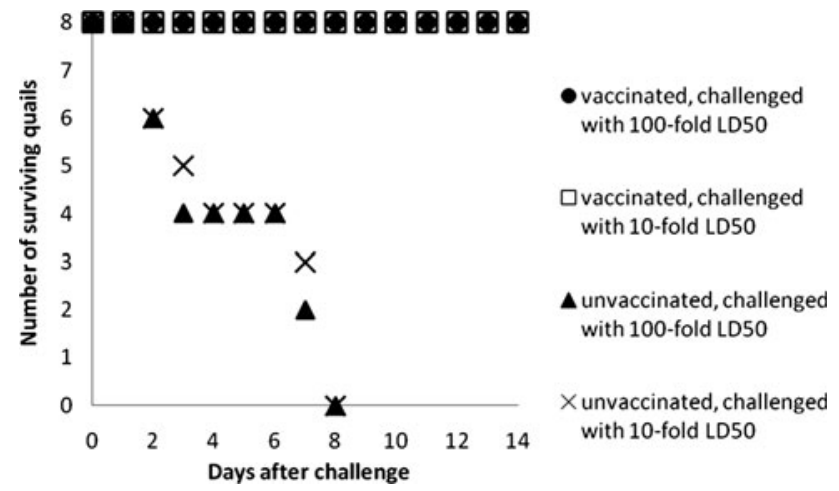

Fig. 1 Protection of Chinese painted quails immunized with the NIBRG-14 (clade 1) vaccine against the highly pathogenic heterologous A/Swan/Nagybaracska/01/06(H5N1) (clade 2.2) strain. Sixteen birds vaccinated s.c. with a single dose of NIBRG-14 vaccine (6 HA/ dose) were challenged in two groups of eight birds with 10 or 100 times the $\mathrm{LD}_{50}$ of the $\mathrm{A} / \mathrm{Swan} / \mathrm{Nagybaracska} / 01 / 06(\mathrm{H} 5 \mathrm{~N} 1)$ strain at 3 weeks post-immunization. Sixteen unvaccinated birds were similarly challenged. Mortality was monitored on a daily basis for 14 days
Sera from 8 birds at 3 weeks after single-dose immunization were tested for anti-HA and neutralization antibodies against the vaccine and challenge strains. Haemagglutination inhibition (HI) tests were performed by standard procedures with chicken red blood cells and 4 HA units of virus/well [16]. The microneutralization (MN) assay was performed as described [31]. Positive antibody controls for HI and MN assays were prepared by immunization of birds with s.c. injection of an emulsion containing $0.5 \mathrm{mg}$ of whole, formaldehyde-inactivated influenza NIBRG-14 four times with complete or incomplete Freund's adjuvant (Calbiochem, La Jolla, CA, USA). The titre of the positive antibodies against the NIBRG-14 strain was $>1: 40$ in the HI and MN assays. Sera obtained from non-immunized birds did not react in these assays. Statistical analysis was performed with the SPSS program, version 17.0. Differences between groups in continuous variables were calculated using the nonparametric MannWhitney U-test; $\mathrm{p}<0.05$ was taken as significant.

All birds responded with an HI titre of 10.6-32, geometric mean titre (GMT) of 21.1 against the NIBRG-14 homologous strain, but the HI titres against the A/Swan/ Nagybaracska/01/06(H5N1) strain were significantly lower, some $<1: 4(\mathrm{GMT}=4.4)$. When the same sera were examined by MN, the animals gave a GMT of 20.7 against the vaccine strain, and the five animals that exhibited seroconversion against the A/Swan/Nagybaracska/01/06(H5N1) strain in the HI test were also positive in the $\mathrm{MN}$ assay. The sera from three birds with a titre of $<1: 4$ against the challenge virus in the HI tests showed similarly undetectable titres in the MN assays (Table 2). Positive control antibodies exhibited the expected $\mathrm{HI}$ and MN titres against the NIBRG-14 strain; negative antibody controls did not react in the assays (not shown).

Correlates for protection from disease and death by $\mathrm{H} 5 \mathrm{~N} 1$ isolates are complex. HI titres of $\geq 1: 40$ in $>70 \%$

Table 1 Protection from virus excretion in the intestinal tract after challenge of Chinese painted quails immunized with a single dose of the NIBRG-14 strain

\begin{tabular}{lll}
\hline $\begin{array}{l}\text { Quails challenged with A/Swan/ } \\
\text { Nagybaracska/01/06(H5N1) }\end{array}$ & $\begin{array}{l}\text { Viral antigens no. of + samples/total } \\
\text { no of samples/no. of quails }\end{array}$ & $\begin{array}{l}\text { Viral RNA no. of + samples/total } \\
\text { no. of samples/no. of quails }\end{array}$ \\
\hline Immunized and challenged with 100 LD & $0 / 40 / 8$ & $0 / 40 / 8$ \\
Immunized and challenged with 10 LD & $0 / 40 / 8$ & $0 / 40 / 8$ \\
Non-immunized and challenged with 100 LD & $14 / 14 / 6$ & $14 / 14 / 6$ \\
Non-immunized and challenged with 10 LD & $16 / 16 / 7$ & ND
\end{tabular}

Quails were immunized with a single dose of the NIBRG-14 vaccine and challenged with the A/Swan/Nagybaracska/01/06(H5N1) strain. Cloacal swab samples were collected on days $0,2,4,6,8$ and 10, but samples were not taken from dead animals. Thirty-two samples from the four groups obtained on day 0 were all negative for viral antigen and RNA (not shown). Results obtained from samples collected on days $2-10$ are included in the table

$N D$ not done 
Table 2 Serum antibody responses against the homologous NIBRG14 and heterologous A/Swan/Nagybaracska/01/06(H5N1) strains in Chinese painted quails after immunization with a single dose of the NIBRG-14 vaccine

\begin{tabular}{|c|c|c|c|c|}
\hline \multirow[t]{3}{*}{ Quail no. } & \multicolumn{4}{|c|}{ Serum antibody titre against } \\
\hline & \multicolumn{2}{|c|}{ NIBRG-14 } & \multicolumn{2}{|c|}{ A/Swan/Nagybaracska/01/06(H5N1) } \\
\hline & $\mathrm{HI}$ & MN & $\mathrm{HI}$ & $\mathrm{MN}$ \\
\hline 1 & 16 & 13.3 & 8 & 4 \\
\hline 2 & 32 & 26.6 & 10.6 & 10.6 \\
\hline 3 & 32 & 32 & 6.6 & 8 \\
\hline 4 & 10.6 & 10.6 & 4 & 4 \\
\hline 5 & 16 & 21.3 & $<4$ & $<4$ \\
\hline 6 & 21.3 & 26.6 & $<4$ & $<4$ \\
\hline 7 & 21.3 & 32 & $<4$ & $<4$ \\
\hline 8 & 32 & 16 & 8 & 8 \\
\hline GMT & $21.1 *$ & $20.7 * *$ & $4.4^{*}$ & $4.1 * *$ \\
\hline
\end{tabular}

Serum samples from 8 of the 24 immunized quails were collected 3 weeks after a single dose of vaccine. The titres were determined against the homologous and heterologous viruses. Each dilution of the sera was tested in three parallel HI and MN assays, and GMTs were calculated from the data from eight quails. For titres $<1: 4$, an arbitrary value of $1: 2$ was used for calculation. $* \mathrm{p}=0.001,{ }^{*} \mathrm{p}=0.001$

of adult subjects are required for the licensing of currently available influenza vaccines [3]. Our results, confirming earlier results [2, 20,25], suggest that these requirements may not be critical for avian $\mathrm{H} 5 \mathrm{~N} 1$ viruses and indicate that the low levels or insufficient detection of anti-HA antibodies following immunization with the NIBRG-14 vaccine are not limited to mammals, but are also observed with Chinese painted quail, an avian species that is highly susceptible to a HPAI H5N1 strain. Protection from a lethal viral challenge may possibly be independent of the prechallenge anti-HA antibody levels, and other mechanisms, such as anti-NA antibodies, are involved in protection [24, 25]. Alternatively, anti-HA antibodies were present at a seroprotective level in the sera, but the $\mathrm{HI}$ and MN assays detected avian $\mathrm{H} 5 \mathrm{~N} 1$ antibody with low sensitivity, as suggested earlier [20, 25]. Similarly to our results, crossreacting antibodies against $\mathrm{A} / \mathrm{Swan} / \mathrm{Nagybaracska/01/}$ 06(H5N1) were detected in in vitro assays in only about $25 \%$ of humans who were reactive to the homologous NIBRG-1 strain [6]. Furthermore, the vaccine and challenge viruses possessed antigenically distinct $\mathrm{HA}$ and NA genes from the clade $1 \mathrm{~A} /$ Vietnam/1194/2004 and clade 2 $\mathrm{A} / \mathrm{Swan} / \mathrm{Nagybaracska/01/06(H5N1)}$ strains, respectively, but the cell-mediated immune responses directed to the internal proteins of the strains, or to common cytotoxic $\mathrm{T}$ cell epitopes in the vaccine and challenge HA, may contribute to or be responsible for the cross-clade protection. Antibody-dependent cellular cytotoxicity was detected in humans in the absence of neutralization to various strains, including a H5N1 HA [12]. New approaches using recombinant technologies to identify universal influenza vaccines that improve the level of cross-protection are being investigated [15].

The limitations of our study include the lack of investigations on the mechanism of protection in the presence of low or undetectable levels of anti-HA antibodies against the challenge virus. Moreover, some wild-type H5N1 isolates may be more pathogenic in quails than the A/Swan/ Nagybaracska/01/06(H5N1) challenge virus, hence requiring higher levels of immune responses for protection. Aspects of these limitations demand further studies.

In summary, we report that (1) small Chinese painted quails may serve for testing vaccine-induced protection against avian $\mathrm{H} 5 \mathrm{~N} 1$ virus strains, and (2) a single dose of NIBRG-14 vaccine containing $6 \mu \mathrm{g}$ HA induces anti-HA and neutralizing antibodies at low titres against the homologous strain in all quails and seroconversion against the heterologous strain in only some of the quails, but it confers $100 \%$ protection in those challenged with high doses of the highly pathogenic heterologous (clade 2) strain A/Swan/Nagybaracska/01/06(H5N1). Thus, the conventionally used anti-HA titer might not be a good indicator for protection against influenza A (H5N1) virus.

Acknowledgments This research was supported by the Hungarian Ministry of Health, the Office of the Chief Medical Officer, Hungary, and the FLUSECURE and FASTVAC consortia, which were funded by the Health Programme of the European Union and the participating member states. The authors thank Dr. John Wood, National Institute for Biological Standards and Control, London, UK, for providing the NIBRG-14 strain.

Conflict of interest The authors declare that they have no conflict of interest.

Open Access This article is distributed under the terms of the Creative Commons Attribution License which permits any use, distribution, and reproduction in any medium, provided the original author(s) and the source are credited.

\section{References}

1. Boon ACM, Finkelstein D, Zheng M, Liao G, Allard J, Klumpp K, Webster R, Peltz G, Webby RJ (2011) H5N1 influenza virus pathogenesis in genetically diverse mice is mediated at the level of viral load. MBio 2(5): e00171-11. doi:10.1128/mBio/mBio.00171-11

2. Bright RA, Carter DM, Crevar CJ, Toapanta FR, Steckbeck FD, Cole KS, Kumar NM, Pushko P, Smith G, Tumpey TM, Ross TM (2008) Cross-clade protective immune respomses to influenza viruses with H5N1 HA and NA elicited by an influenza virus-like particle. PLoS ONE 3(1):e1501. doi:10.1371/journal.pone.0001501

3. Committee for Proprietary Medicinal Products. 12 March 1997. Note for guidance on harmonisation of requirements for influenza vaccines. CPMP/BWP/214/96. European Agency for the Evaluation of Medicinal Products, London, UK. http://www.emea. europa.eu/pdfs/human/bwp/021496en.pdf 
4. Dybing JK, Schultz-Cherry S, Swayne DE, Suarez DL, Perdue ML (2000) Distinct pathogenesis of Hong-Kong-origin H5N1 viruses in mice compared to that of other highly pathogenic H5 avian influenza viruses. J Virol 74:1443-1450. doi:10.1128/JVI. 74.3.1443-1450.2000

5. European Committee for Proprietary Medicinal Products. Guideline on dossier structure and content for pandemic influenza vaccine marketing authorisation application (CPMP/VEG/4717/ 03). European Agency for the Evaluation of Medicinal Products, 2004, London, UK

6. Fazekas G, Martosne-Mendi R, Jankovics I, Szilvásy I, Vajo Z (2009) Cross- reactive immunity to clade 2 strains of influenza virus A subtype H5N1 induced in adults and elderly patients by Fluval, a prototype pandemic influenza virus vaccine derived by reverse genetics, formulated with a phosphate adjuvant, and directed to clade 1 strains. Clin Vaccine Immunol 16:437-443. doi:10.1128/CVI.00327-08

7. Gabriel G, Dauber B, Wolff T, Planz O, Klenk HD, Stech J (2005) The viral polymerase mediates adaptation of an avian influenza virus to a mammalian host. Proc Nat Acad Sci 102: 18590-18595. doi:10.1073/pnas.0507415102

8. Hikono H, Mase M, Matsuu A, Nakayama M, Saito T (2013) Intraocular vaccination with an inactivated highly pathogenic avian influenza virus induces protective antibody responses in chickens. Vet Immunol Immunopathol 151:83-89. doi:10.1016/ jvetimm.2012.10.005

9. Ichinohe T, Ainai A, Ami Y, Nagata N, Iwata N, Kawaguchi A, Suzaki Y, Odagiri T, Tashiro M, Takahashi H, Strayer DR, Carter WA, Chiba J, Tamura S, Sata T, Kurata T, Hasegawa H (2010) Intranasal administration of adjuvant-combined vaccine protects monkeys from challenge with the highly pathogenic influenza $\mathrm{A}$ H5N1 virus. J Med Virol 82:1754-1761. doi:10.1002/jmv.21824

10. Ichinohe T, Ainai A, Tashiro M, Sata T, Hasegawa H (2009) PolyI: polyC12U adjuvant-combined intranasal vaccine protects mice against highly pathogenic $\mathrm{H} 5 \mathrm{~N} 1$ influenza virus variants. Vaccine 27:6276-6279. doi:10.1016/j.vaccine.2009.04.074

11. Isoda N, Sakoda Y, Kishida N, Bai GR, Matsuda K, Umemura T, Kida H (2006) Pathogenicity of a highly pathogenic avian influenza virus, A/chicken/Yamaguchi/7/04 (H5N1) in different species of birds and mammals. Arch Virol 151:1267-1279. doi: 10.1007/s00705-005-0723-6

12. Jegaskanda $S$, Job ER, Kramski M, Laurie K, Isitman G, de Rose R, Winnal WR, Stratov I, Brooks AG, Reading PC, Kent SJ (2013) Cross-reactive influenza-specific antibody-dependent cellular cytotoxicity antibodies in the absence of neutralizing antibodies. J Immunol. doi:10.4049/jimmunol.1201574

13. Jeong OM, Kim MC, Kim MJ, Kang HM, Kim HR, Kim YJ, Joh SJ, Kwon JH, Lee YJ (2009) Experimental infection of chickens, ducks and quails with the highly pathogenic H5N1 avian influenza virus. J Vet Sci 10:53-60. doi:10.4142/jvs.2009.10.1.53

14. Kajihara M, Sakoda Y, Soda K, Minari K, Okamatsu M, Takada A, Kida H (2013) The PB2, PA, NP, and NS genes of a highly pathogenic avian influenza virus $\mathrm{A} /$ whooper swan/Mongolia/3/ 2005(H5N1) are responsible for pathogenicity in ducks. Virol J 10:45. doi:10.1186/1743-422X-10-45

15. Kang S-M, Song J-M, Compans RW (2011) Novel vaccines against influenza viruses. Virus Res 162:31-38. doi:10.1016/ j.virusres.2011.09.037

16. Klimov A, Cox N (2003) Serologic diagnosis of influenza virus infections by hemagglutination inhibition. In: Influenza laboratory course. Centers for Disease Control and Prevention, Atlanta, pp 1-5

17. Lee DH, Park JK, Kwon JH, Yuk SS, Erdene-Ochir TO, Yang YH, Seong BL, Lee JB, Park SY, Choi IS, Song CS (2013) Efficacy of single dose of a bivalent vaccine containing inactivated Newcastle Disease Virus and reassortant highly pathogenic avian influenza H5N1 virus against lethal HPAI an NDV infection in chickens. PLos One 8:e58186. doi:10.1371/journal.pone. 0058186

18. Lycett SJ, Ward MJ, Lewis FI, Poon AFY, Kosakovsky Pond SL, Leight Brown AJ (2009) Detection of mammalian virulence determinants in highly pathogenic avian influenza H5N1 viruses: multivariate analysis of published data. J Virol 83:9901-9910. doi:10.1128/JVI.00608-09

19. Makarova NV, Ozaki H, Kida H, Webster RG, Perez DR (2003) Replication and transmission of influenza viruses in Japanese quail. Virology 310:8-15. doi:10.1016/S0042-6822(03)00094-1

20. Ninomiya A, Imai M, Tashiro $M$, Odagiri $T$ (2007) Inactivated influenza $\mathrm{H} 5 \mathrm{~N} 1$ whole-virus vaccine with aluminum adjuvant induces homologous and heterologous protective immunities against lethal challenge with highly pathogenic $\mathrm{H} 5 \mathrm{~N} 1$ avian influenza viruses in a mouse model. Vaccine 25:3554-3560. doi: 10.1016/j.vaccine.2007.01.083

21. Nishimura H, Itamura S, Iwasaki T, Kurata T, Tashiro M (2000) Characterization of human influenza A (H5N1) virus infection in mice: neuro-, pneumo- and adipotropic infection. J Gen Virol 81:2503-2510

22. Pederson G, Major D, Roseby S, Wood J, Madhun AS, Cox RJ (2011) Matrix-M adjuvanted virosomal H5N1 vaccine confers protection against lethal challenge in a murine model. Influenza Other Resp Viruses 5:426-437. doi:10.1111/j.1750-2659.2011.00256.x

23. Reed LJ, Muench H (1938) A simple method of estimating fifty percent endpoints. Am J Hyg 27:493-497

24. Sandbulte MR, Jimenz GS, Boon AC, Smith LR, Treanor JJ, Webby RJ (2007) Cross-reactive neuraminidase antibodies afford partial protection against $\mathrm{H} 5 \mathrm{~N} 1$ in mice and are present in unexposed humans. PLoS Med 4(2):e59. doi:10.1371/journal.pmed. 0040059

25. Takahashi Y, Hasegawa H, Hara Y, Ato M, Ninomiya A, Takagi H, Odagiri T, Sata T, Tashiro M, Kobayashi K (2009) Protective immunity afforded by inactivated H5N1 (NIBRG-14) vaccine requires antibodies against both hemagglutinin and neuraminidase in mice. J Inf Dis 199:1629-1637. doi:10.1086/598954

26. Tsudzuki M (1994) Excalfactoria quail as a new laboratory research animal. Poult Sci 73:763-768. doi:10.3382/ps.0730763

27. Ungchusak K, Auewarakul P, Dowell SE, Kitphati R, Auwanit W, Puthavathana P, Uiprasertkul M, Boonnak K, Pittayawonganon C, Cox NJ, Zaki SR, Thawatsupha P, Chittaganpitch M, Khontong R, Simmermann JM, Chunsutthhiwat S (2005) Probable person-to-person transmission of avian influenza A (H5N1). $\mathrm{N}$ Eng J Med 352:333-340

28. Vajo Z, Kosa L, Visontay I, Jankovics M, Jankovics I (2007) Inactivated whole virus influenza A (H5N1) vaccine. Emerg Infect Dis 13:807-808. doi:10.3201/eid1305.061248

29. Vajo Z, Wood J, Kosa L, Szilvasy I, Parragh G, Pauliny Z, Bartha K, Visontay I, Kis A, Jankovics I (2010) A single-dose influenza A (H5N1) vaccine safe and immunogenic in adult and elderly patients: an approach to pandemic vaccine development. J Virol 84:1237-1242. doi:10.1128/JVI.01894-09

30. Wan H, Perez D. R (2006) Quail carry sialic acid receptors compatible with binding of avian and human influenza viruses. Virology 346:278-286. doi:10.1016/j.virol.2005.10.035

31. WHO Manual on Animal Influenza Diagnosis and Surveillance. http://www.who.int/vaccine_research/diseases/influenza/WHO_ manual_on_animal-diagnosis_and_surveillance_2002_5.pdf

32. Yamada S, Shinya K, Takada A, Ito T, Suzuki T, Suzuki Y, Le QM, Ebina M, Kasai N, Kida H, Horimoto T, Rivailler P, Chen LM, Donis RO, Kawaoka Y (2012) Adaptation of a duck influenza A virus in quail. J Virol 86:1411-1420. doi:10.1128/JVI.06100-11

33. Zitzow LA, Rowe T, Morken T, Shieh WJ, Zaki S, Katz JM (2002) Pathogenesis of avian influenza A (H5N1) viruses in ferrets. J Virol 76:4420-4429. doi:10.1128/JVI.76(9),4420-4429.2002 